\title{
Development of a standard protocol for quantitative polymerase chain reaction to detect adenovirus 36, which is associated with obesity
}

\author{
K.-A. HWANG ${ }^{1,2 *}$, S. PARK ${ }^{1 *}$, J. H. AHN ${ }^{2}$, J.-H. NAM ${ }^{1 *}$ \\ ${ }^{1}$ Department of Biotechnology, The Catholic University of Korea, 43-1 Yeokgok 2-dong, Wonmi-gu, Bucheon, Gyeonggi-do, 420-743, \\ Korea; ${ }^{2}$ Department of Research and Development, Genetree Research, Seoul, Korea
}

Received February 26, 2018; revised March 26, 2018; accepted September 5, 2018

\begin{abstract}
Summary. - It has been previously reported that adenovirus 36 (Ad36) infection is associated with obesity in humans and other animals. However, there is no clinically available standard protocol to detect Ad36 DNA. In this study, we developed a method for quantitative and rapid detection of Ad36 DNA. Using a TaqMan probe quantitative polymerase chain reaction (qPCR), we identified that the E3 and E4orf1 regions specifically detect Ad36 DNA, because these regions did not show cross reactivity with other types of adenoviruses. The limit of detection was 379 copy $/ \mathrm{ml}$ and $384 \mathrm{copy} / \mathrm{ml}$ for E3 and E4orf1 regions of Ad36, respectively. The \%CV (coefficient of variation) for reproducibility of the assay using adenovirus reference material ranged from 1.07-13.02. After we developed the standard protocol to detect Ad36 DNA, we used mouse as a surrogate model to confirm its clinical applicability. We administered Ad36 to mice via intranasal and oral routes, with intraperitoneal administration as the positive control, to analyze the effect of infection route. Ad36 DNA could be detected in lungs, liver, pancreas, and epididymal fat tissue after intraperitoneal injection, whereas it was found only in lungs after intranasal injection. No Ad36 DNA was detectable in any tested organ after oral injection. This indicates that the main route of infection with Ad36 is intranasal, suggesting that Ad36 is a respiratory virus. The standard protocol for qPCR developed in this study is useful for clinical detection of Ad36 DNA.
\end{abstract}

Keywords: adenovirus 36; real-time PCR; obesity

\section{Introduction}

Adenoviruses are medium-sized, icosahedral viruses $70-100 \mathrm{~nm}$ in diameter, which possess $26-45 \mathrm{~kb}$ doublestranded DNA genome within a non-enveloped protein capsid (Robinson et al., 2011). More than 60 different serotypes of human adenoviruses have been identified and grouped into seven different species (human adenoviruses A to G) (Walsh et al., 2010; Robinson et al., 2013). The human adenovirus genome encodes six early transcription units (E1A, E1B, E2B, E2A, E3, and E4), which regulate DNA transcription, and five late transcription units (L1-L5)

"Corresponding author. E-mail: jhnam@catholic.ac.kr; phone: +82-2-2164-4917. \#These authors contributed equally to this work. Abbreviations: $\mathrm{Ad} 36$ = adenovirus 36; dpi = days post infection; $\mathrm{CV}$ = coefficient of variation; $\mathrm{qPCR}=$ quantitative PCR that direct structural proteins (Davison et al., 2003). The E3 transcription units in different human adenovirus species vary in length, number of open reading frames, and nucleotide sequence (Robinson et al., 2011). Among the structural proteins, the hexon protein functions as a coat protein on the viral surface, and the fiber protein mediates the initial attachment step to host cells for viral internalization (Roberts et al., 1986; Nemerow et al., 2009).

Adenoviruses have been recognized to cause high rates of morbidity and mortality in immunosuppressed patients (Echavarria, 2008). Moreover, adenovirus infections can involve a number of organ systems and may lead to serious illness (Gu et al., 2003). Adenovirus 36 (Ad36), classified as the species of human adenovirus D, is regarded as adipogenic: epidemiologic studies have shown that Ad36 infection is associated with obesity in humans and some animals (Ponterio and Gnessi, 2015), and many studies 
have reported that Ad36 infection increases body weight, the number of fat cells and the level of fat in various organs of rats and rhesus and marmoset monkeys (Pasarica et al., 2006; Dhurandhar et al., 2002). The early region 4 open reading frame 1 (E4orf1) gene of Ad36 is necessary and sufficient for adenovirus 36 ( $\mathrm{Ad} 36)$-induced adipogenesis (Rogers et al., 2008).

Although obesity is recognized as a disease with multiple etiologies, the role of microbial and viral infection as an etiological factor has recently received consideration (Adrych, 2005; Astrup et al., 1998; Powledge, 2004). Ad36 infection has been shown to upregulate several obesity-related genes including LPL, ATF3, FABP4, $\mathrm{C} / \mathrm{EBP} \alpha$, and $\mathrm{C} / \mathrm{EBP} \gamma$ (Na et al., 2012). Furthermore, when E4orf1 of Ad 36 was selectively knocked down by RNAi, the Ad36-induced adipogenic signaling cascade was abolished in 3T3-L1 cells (Rogers et al., 2008). This demonstrates that Ad36 E4orf1 is associated with Ad36-induced adipogenesis (Rogers et al., 2008).

Virus neutralization test represents the gold standard method for serotyping adenovirus isolates (Wadell, 1984). The laboratory diagnosis of adenovirus infection has typically relied on the detection of a cytopathic effect in a variety of cell lines. Therefore, virus isolation may be associated with reduced sensitivity as a diagnostic technique, resulting in false negative results. In contrast, antibody titers persist for weeks to months or even years, and can be quite reliably detected e.g. by serum neutralization assays, thereby being a useful tool for (retrospective) diagnosis of adenovirus infection and epidemiological studies. It was reported that in the USA obese adults have a higher prevalence of neutralizing antibodies to Ad36 (30\%) compared with non-obese adults (11\%) (Atkinson et al., 2005). We previously reported that in Korea, $28.6 \%$ of obese Korean school children were positive for Ad36 antibody compared with 13.6\% of nonobese school children ( $\mathrm{Na}$ et al., 2010). Another study reported that $30 \%$ of overweight or obese Korean children were positive for Ad36 antibodies (Atkinson et al., 2010). However, virus isolation using cell culture and serotyping by neutralization is complex and time-consuming, requiring 2-4 weeks (Miura-Ochiai et al., 2007), and the serum neutralization test is somewhat tedious. Therefore, a more reliable method requiring a shorter time to detect Ad36 infection would be desirable. Several studies have reported the detection of Ad36 DNA in mouse organs and in human adipocyte tissue using polymerase chain reaction (PCR)based methods (Krishnapuram et al., 2011; Salehian et al., 2010; Ponterio et al., 2015). However, there is no clinically available standard protocol to detect Ad36 DNA, and, because of this lack of a standard detection procedure, the initial target organs and entry routes of Ad36 infection remain unclear. Moreover, although several methods for adenovirus DNA detection have been developed ( $\mathrm{Gu}$ et al., 2003; Miura-Ochiai et al., 2007; Heim et al., 2003), to the best of our knowledge no standard method for the quantitative detection and identification of Ad36 has been reported.

In this study, we evaluated the analytical sensitivity and specificity of a quantitative PCR (qPCR) using the TaqMan probe. The qPCR assay developed in this study amplified two target regions, E3 and E4orf1, which are associated with a variety of early viral functions (Wold and Gooding, 1991; Halbert et al., 1985). After developing the standard detection method, we used it to detect the presence of Ad36 DNA in various organs of mice infected through intranasal, oral, and intraperitoneal routes, to evaluate the potential clinical applicability of this qPCR and provide information about the natural infection route and initial target organ of Ad36 infection.

\section{Materials and Methods}

Animals and maintenance. Four-week-old female C57BL/6 mice were purchased from the Orient Bio (Sungnam, Korea) and maintained in a specific-pathogen-free facility with a standard light cycle (12 h light/dark) and free access to water and food (5\% fat content, Harlan Laboratories, USA) for 90 days after Ad36 infection, according to protocols approved by the Institutional Animal Care and Use Committee, Sungsim Campus, Catholic University of Korea (No. 2013-009).

We investigated the distribution of Ad36 DNA in four organs after infection via three routes: intraperitoneal (positive control), intranasal, and oral. Tissues examined, included epididymal fat, liver, and pancreas, which are organs with major metabolic roles, and lungs, which are the major target of respiratory viruses. The mice were administered with $5 \times 10^{6}$ plaque-forming units (PFU) of Ad36 per mouse or cell culture medium (sham treatment). Mice were euthanized $1,3,7,30$, and 90 days after virus infection $(n=3$ mice/group at each time point) to determine the distribution of the viral DNA.

DNA extraction methods. We evaluated five commercial DNA extraction kits for their ability to recover Ad36 DNA. The kits included in the comparison were the FTA filter, Chelex-100, DNAzol, Chemagic DNA blood kit, and QIAamp DNA mini kit for detection of Ad36 DNA (detailed in Table 1). The five extraction methods were performed in triplicates on $200 \mu$ aliquots of pooled Ad36-infected cell supernatants obtained by centrifuging cultures at $8,000 \mathrm{rpm}$ for $5 \mathrm{~min}$. Method 1. FTA filter; $200 \mu \mathrm{l}$ of supernatant were loaded on the collection area of an FTA Filter (Thermo Fisher Scientific, USA). After drying, five $1.2 \times 1.2 \mathrm{~mm}$ pieces of dried sample paper were placed into $1.5 \mathrm{ml}$ PCR tubes. DNA was recovered from the matrix using a simple hot water elution procedure. Inhibitory components were removed by a short washing step (van Tongeren et al., 2011). Method 2. DNAzol; $200 \mu \mathrm{l}$ of culture supernatant were treated with DNAzol ${ }^{\circledR}$ reagent (Thermo Fisher Scientific). The genomic DNA was precipitated from the lysate using ethanol. Following an 
Table 1. DNA extraction methods used in this study

\begin{tabular}{llll}
\hline Method & Kit name & Basis and format & Elution volume $(\mu \mathrm{l})$ \\
\hline FTA filter & Whatman FTA card & card binding; boiling technology & $50 \mu \mathrm{l}$ in TE buffer \\
Chelex-100 & Chelex 100 chelating ion-exchange resin & solution-based; ion-exchange columns & $50 \mu$ in distilled $\mathrm{H}_{2} \mathrm{O}$ \\
DNAzol & DNAzol ${ }^{\mathrm{TM}}$ reagent & solution-based; selective precipitation of DNA & $50 \mu \mathrm{l}$ of $8 \mathrm{mmol} / \mathrm{NaOH}$ \\
Chemagen & Chemagic DNA blood kit & solution-based; magnetic glass particle technology & $50 \mu$ in elution buffer \\
QIAGEN & QIAamp DNA mini kit & silica membrane binding; spin column format & $50 \mu \mathrm{l}$ in AE buffer \\
\hline
\end{tabular}

ethanol wash, the DNA was solubilized in water (Sun et al., 2014). Method 3. Chelex-100; $200 \mu$ l of culture supernatant were added to $10 \%$ (wt/vol) of Chelex 100 (Bio-Rad Laboratories, USA). The mixture was then incubated at $55^{\circ} \mathrm{C}$ for $15 \mathrm{~min}$, vortexed, boiled for $8 \mathrm{~min}$, and centrifuged for $2 \mathrm{~min}$ at 14,000 x $\mathrm{g}$ (Echavarria et al., 1998). The supernatant containing the DNA was used for PCR. Methods 4 and 5. Chemagen (PerkinElmer, Germany) and QIAGEN methods (Qiagen, Germany); $200 \mu$ l of culture supernatant were applied to two commercial kits (Chemagic DNA blood kit and QIAamp DNA mini kit). The Chemagic DNA blood kit uses magnetic beads and the QIAamp DNA mini kit uses a column to purify Ad36 DNA. Both protocols were performed according to the manufacturers' instructions. After purification of viral DNA, the quantity of purified DNA was measured using a Nanodrop 2000 spectrophotometer (Thermo Fisher Scientific, USA).

Purification of viral DNA from infected mouse organs. We extracted total DNA from four tissues including epididymal fat, liver, pancreas, and lung using the QIAamp DNA mini kit. Small pieces of all tissues were placed in $200 \mu \mathrm{l}$ phosphate-buffered saline and $200 \mu$ tissue lysis buffer was added. The DNA was bound to a spin column filter, and then washed with $99.9 \%$ ethanol followed by two wash buffers. Total DNA was stored at $-80^{\circ} \mathrm{C}$ until analysis.

Real-time $q P C R$. The $\mathrm{qPCR}$ assay included an internal control for the detection of Ad36 DNA. The qPCR was performed using an Applied Biosystems ${ }^{\oplus} 7500$ cycler (Thermo Fisher Scientific, USA). The sequences of primers and probes for several targets in Ad36 are listed in Table 2; these sequences were designed using Primer Express software (v. 2.0; Applied Biosystems, USA) based on the nucleotide sequence of the Ad36 genome (Acc. No. GQ384080). We used an Ad36 TaqMan probe (with 6-carboxyfluorescein [FAM] attached to the 5 ' end and black-hole quencher 1 [BHQ1] attached to the 3 ' end) for quantification of Ad36 DNA and a $\beta$-actin TaqMan probe $\left(\mathrm{HEX}^{\mathrm{TM}}\right.$ attached to the $5^{\prime}$ end and BHQ1 attached to the 3 ' end) for amplification of $\beta$-actin DNA. $\beta$-actin is used to check successful isolation of mouse genomic DNA and serves as an internal control. The details of primer sets and probes are given in Table 2. All qPCR reactions were carried out using the TaqMan universal PCR master mix containing uracil-DNA glycosylase (Thermo Fisher Scientific, USA). The total reaction volume of $25 \mu \mathrm{l}$ containing $5 \mu$ l of template DNA, $12.5 \mu$ lof $2 \times$ TaqMan universal

Table 2. Sequences of the primers and probes used in the quantitative PCR assay

\begin{tabular}{|c|c|c|c|c|}
\hline Target gene & Region & Primer or probe & Sequence $\left(5^{\prime}-3^{\prime}\right)$ & Position \\
\hline \multirow{15}{*}{$\begin{array}{l}\text { Adenovirus } 36 \\
\text { (GQ384080) }\end{array}$} & \multirow{3}{*}{ E3 } & E3 forward primer & TTACCGGCAGCAGCACAGT & $26796-26814$ \\
\hline & & E3 reverse primer & GACTACCCCCCTCTGTCAGAGA & $26882-26903$ \\
\hline & & E3 probe & FAM-AACTAACСTTCTTTCTGATACTAACACTCCTAAAACCGGA-BHQ1 & $26824-26863$ \\
\hline & \multirow[t]{3}{*}{ E4orf1 } & E4orf1 forward primer & AAAGAGCAGCACAGAGAGATCA & $34417-34438$ \\
\hline & & E4orf1 reverse primer & GAGTGAGCGTGCTGGTTC & $34533-34550$ \\
\hline & & E4orf1 probe & FAM-TTCAAGGCCATAAATCTGCCCTGATATCCA-BHQ1 & $34499-34528$ \\
\hline & \multirow[t]{3}{*}{ Hexon 1} & Hex-1 forward primer & TCCAGATGTCAGGATCATTGAGA & $18936-18958$ \\
\hline & & Hex -1 reverse primer & TGCTGCCAGATCCATCCA & $19001-19019$ \\
\hline & & Hex-1 probe & FAM-CGGTGTTGAAGATGAGCTTCCAAATTATTGCTT-BHQ1 & $18963-18995$ \\
\hline & \multirow[t]{3}{*}{ Hexon 2} & Hex-2 forward primer & TGGCGAAGTTGCTTCTCAGA & 19080-19099 \\
\hline & & Hex -2 reverse primer & AGGTTGGCCTGAAGGTTTATCTC & $19132-19153$ \\
\hline & & Hex-2 probe & FAM-TCAGATCGCCAAGGGTAATCTGTATGCC-BHQ1 & $19101-19128$ \\
\hline & \multirow[t]{3}{*}{ Fiber } & Fiber forward primer & GGAGACTTAGTAGCTTGGGACAAAAA & $31464-31489$ \\
\hline & & Fiber reverse primer & CTTGCTGTTTCAACTTTGCAATTT & $31532-31555$ \\
\hline & & Fiber probe & FAM-TACACGCACCCTTTGGACAACACCTG-BHQ1 & $31496-31521$ \\
\hline \multirow{3}{*}{$\begin{array}{l}\text { Mus musculus } \\
\text { (NM007393) }\end{array}$} & \multirow{3}{*}{$\beta$-actin } & Forward primer & CGAGCGTGGCTACAGCTT & $691-708$ \\
\hline & & Reverse primer & TCTTTGATGTCACGCACGATTT & $729-750$ \\
\hline & & Probe & HEX- ACCACCACAGCTGAGAGG-BHQ1 & $710-727$ \\
\hline
\end{tabular}


PCR master mix, $0.3 \mu \mathrm{mol} / \mathrm{l}$ of each forward and reverse primer, and $0.1 \mu \mathrm{mol} / \mathrm{l}$ of each probe was added to a real-time PCR plate (Thermo Fisher Scientific, USA). The PCR conditions were $2 \mathrm{~min}$ at $50^{\circ} \mathrm{C}$ and $10 \mathrm{~min}$ at $95^{\circ} \mathrm{C}$, followed by 45 cycles of $20 \mathrm{~s}$ at $95^{\circ} \mathrm{C}$ and $1 \mathrm{~min}$ at $60^{\circ} \mathrm{C}$. To generate the standard curve, the cycle thresholds (Ct) of the plasmid dilutions were measured. All samples were tested in triplicate. A threshold cycle $(\mathrm{Ct})$ value for each sample was calculated by determining the auto-threshold.

Ad36 DNA concentrations used for the standard curve. The DNA PCR product was purified and inserted into the pGEM-T vector system (Promega, USA) according to the manufacturer's protocol. These E3 and E4orf1 plasmids were used as adenovirus reference materials to determine the reproducibility and the limit of detection of the assays. Plasmid DNAs were extracted using an AccuPrep plasmid mini extraction kit (Bioneer, Korea) and the quantity of plasmid DNA measured using a spectrophotometer. A series of log dilutions of E3 and E4orf1 standard plasmid DNA from $10^{6}-10^{2}$ copies/ $\mu$ l was then prepared to establish an external standard curve for the qPCR.

Statistical analysis. For all data, copies/ml are reported as mean \pm standard deviation (SD). All analyses were performed using GraphPad Prism (v. 5.01; GraphPad Software, USA). The values were compared using a $t$-test or one-way analysis of variance (ANOVA) followed by a post-hoc Tukey test for multiple comparisons. Differences were considered significant at $P<0.05$.

\section{Results}

\section{Comparison of viral DNA extraction methods}

Ad36 has a DNA genome. Therefore, we compared five commercial DNA extraction kits to test their efficiency: the FTA filter, Chelex-100, DNAzol, the Chemagic DNA blood kit, and the QIAamp DNA mini kit. The kit names and the basic technologies used in all methods are listed in Table 1. After DNA extraction, qPCR was used to detect E3 and E4orf1 of Ad36, and the log mean, SD, and \%CV values were determined by repeating the measurements four times. Fig. 1 summarizes the yield of purified DNA (copies/ml) obtained for all sample extracts using the five extraction methods.

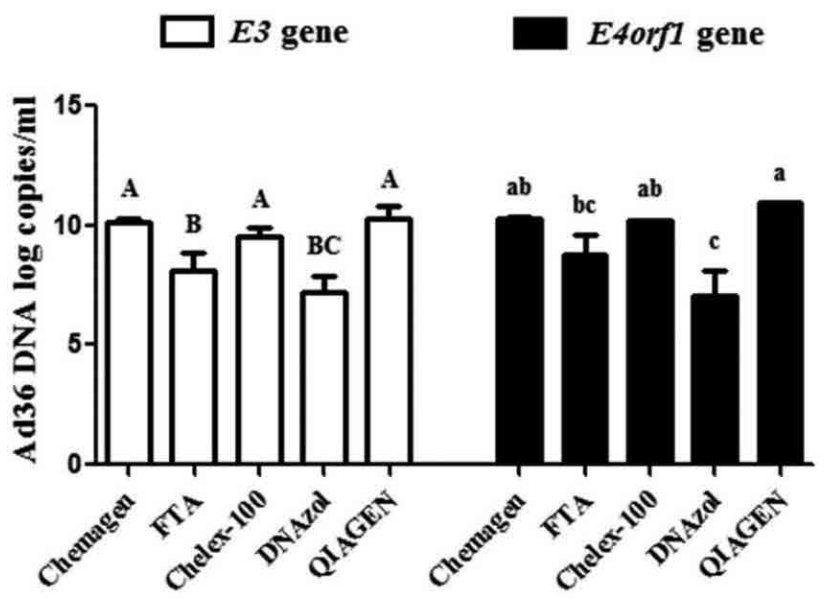

Fig. 1

Comparison of DNA extraction methods to detect Ad36 DNA The detailed extraction methods are shown in Table 1. Two hundred microliters of supernatant from Ad36-infected cells were used to purify Ad36 DNA. The purification yield (copies/ml) was measured in four replicates using reference materials (plasmids containing E3 or E4orf1 genes). The comparison between methods was analyzed by ANOVA test. The different letters on bar graphs indicate statistical significance: capital letters (A, B, C) for E3 and small letters (a, b, c) for E4orf1. All analyses were performed using GraphPad Prism v. 5.01.

The log means of the number of DNA copies extracted from Ad36-infected cells using FTA filter, Chelex-100, DNAzol, Chemagen, and QIAEN methods were 7.87, 9.32, 7.21, 10.08, and 10.10 for the E3 region-specific qPCR and 8.92, 10.24, $7.08,10.35$, and 11.01 for the E4orf1 region-specific qPCR, respectively. Three methods (Chelex-100, Chemagen, and QIAGEN methods) showed particularly high efficiencies of virus DNA extraction. Moreover, the \% $\mathrm{CV}$ of these three methods was $<3 \%$, confirming their good reproducibility. Of the five methods, with the highest DNA copy level was QIAGEN method, although this difference was not significant (Fig. 1 and Table 3). Based on these results, the QIAGEN method was confirmed to be the best available for the extraction and purification of Ad36 DNA.

Table 3. Comparison of five DNA extraction methods for quantitative PCR using E3 and E4orf1 regions

\begin{tabular}{|c|c|c|c|c|c|c|}
\hline \multirow{2}{*}{ Method } & \multicolumn{3}{|c|}{ Adenovirus 36 DNA copies/ml (E3 gene) } & \multicolumn{3}{|c|}{ Adenovirus 36 DNA copies/ml (E4orf1 gene) } \\
\hline & Log mean & Standard deviation & $\% \mathrm{CV}^{\mathrm{a}}$ & Log mean & Standard deviation & $\% \mathrm{CV}^{\mathrm{a}}$ \\
\hline FTA filter & 7.87 & 0.46 & 5.87 & 8.92 & 0.72 & 8.03 \\
\hline Chelex-100 & 9.32 & 0.08 & 0.83 & 10.24 & 0.01 & 0.09 \\
\hline DNAzol & 7.21 & 0.80 & 11.05 & 7.08 & 0.84 & 11.91 \\
\hline Chemagen & 10.08 & 0.02 & 0.23 & 10.35 & 0.08 & 0.80 \\
\hline QIAGEN & 10.10 & 0.09 & 0.94 & 11.01 & 0.12 & 1.07 \\
\hline
\end{tabular}

a $\mathrm{CV}$ : percent coefficient of variation. 
(a)

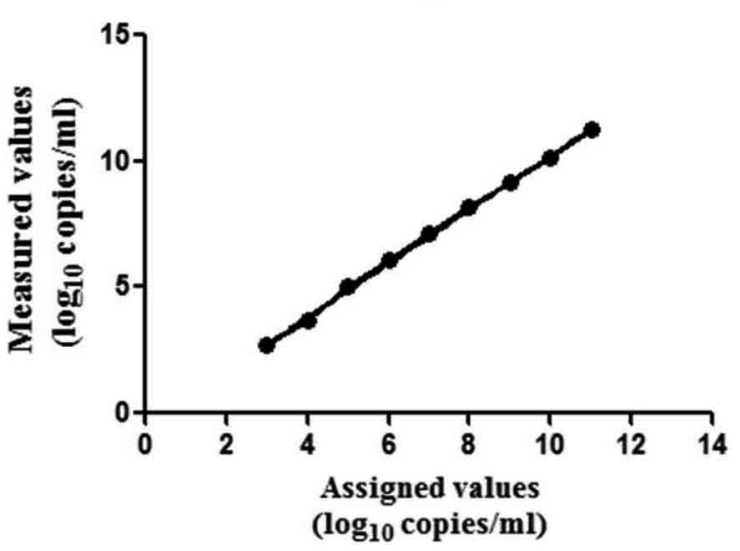

(b)

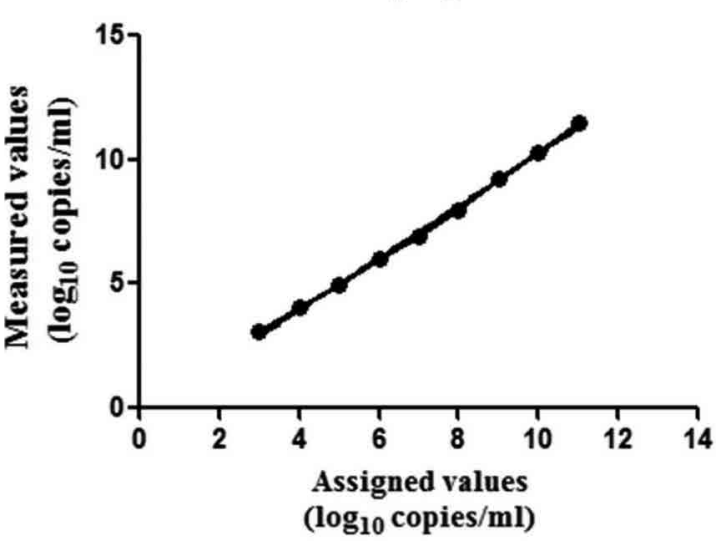

Fig. 2

Linear regression analysis of Ad36 DNA loads by real-time PCR

Serial tenfold dilutions of E3 (a) and E4orf1 (b) plasmid DNAs ranging from $1 \times 10^{3}-1 \times 10^{11}$ copies/ml were analyzed by E3- and E4orf1-specific qPCR. The slope $(\mathrm{y})$ indicates the PCR efficiency and the coefficient of determination $\left(\mathrm{R}^{2}\right)$ indicates the linear regression.

Determination of linearity, sensitivity, and specificity of E3 and E4orf1 region-specific qPCR

Analysis of tenfold serial dilutions $\left(1 \times 10^{3}-1 \times 10^{11}\right.$ copies/ml) of plasmid DNA containing E3 and E4orf1 genes (termed the reference material) confirmed that the E3- and E4orf1-specific qPCRs had similar linearity (Fig. 2), with $\mathrm{R}^{2}$ of 0.9988 and 0.9982 , respectively. Linear regression analysis of the Ad36-specific qPCR demonstrated valid linearity, with slopes between 1.0695 and 1.0501, and y-axis intercept points between 0.4571 and 0.2362 (Fig. 2).

We performed the sensitivity testing using 24 replicates at different concentrations $(10,000,2000,400$, and 80 copies $/ \mathrm{ml}$ ) in two different laboratories. The sensitivities of the qPCR were estimated to be 379 copies/ml for E3 and 384 copies/ml for E4orf1. We have also analyzed the $95 \%$ probit using IBM SPSS Statistics 20 (IBM Corp, USA) (Table 4).

The specificity of Ad36 detection with the E3- and E4orf1specific qPCRs was demonstrated using DNA from adenovirus types $1,2,3,4,5,6,7,10,23$, and 40, which were supplied by Prof. H. Lee (Medical Center, Department of Microbio- logy, University of Ulsan). We tested for five genes: hexon 1 and hexon 2, fiber, E3 and E4orf1, using specific primer sets and probes (Table 2 ) to compare their cross reactivity. Specific primer sets and probes for hexon 1, hexon 2, and fiber showed cross reactivity between adenoviruses 7, 10, 23, 40, whereas E3 and E4orf1 specifically detected only Ad36 (Table 5). These results were expected by the alignment of E3 and E4orf1 sequences of adenoviruses (Fig. 3).

\section{Determination of repeatability and reproducibility}

Intra-assay variation was estimated using reference plasmid DNA containing E3 and E4orf1 genes at concentrations ranging from $1 \times 10^{4}-1 \times 10^{6}$ copies/ml using E3- and E4orf1specific qPCR. The intra-assay variability was determined using 20 replicates per batch, and the inter-assay variability was determined by repeating assays twice a day for 10 days. The intra-assay \%CV was 5.59 for $10^{6}$ copies $/ \mathrm{ml}$ and 13.02 for $10^{4}$ copies $/ \mathrm{ml}$ in the E3-specific qPCR, and 5.00 for $10^{6}$ copies/ $\mathrm{ml}$ and 11.15 for $10^{4}$ copies $/ \mathrm{ml}$ in the E4orf1-specific qPCR. The inter-assay $\% \mathrm{CV}$ was 7.99 for $10^{6}$ copies $/ \mathrm{ml}$ and 9.71 for

Table 4. Probity analysis for determination of the limit of detection

\begin{tabular}{|c|c|c|c|c|c|c|}
\hline \multirow{2}{*}{$\begin{array}{l}\text { Copies/ml of plasmid } \\
\text { DNA }\end{array}$} & \multicolumn{3}{|c|}{ Adenovirus 36 DNA copies/ml (E3 gene) } & \multicolumn{3}{|c|}{ Adenovirus 36 DNA copies/ml (E4orf1 gene) } \\
\hline & Replicates & Positive reaction & $\%$ & Replicates & Positive reaction & $\%$ \\
\hline 10000 & 24 & 24 & 100 & 24 & 24 & 100 \\
\hline 2000 & 24 & 24 & 100 & 24 & 24 & 100 \\
\hline 400 & 24 & 23 & 95.8 & 24 & 23 & 95.8 \\
\hline 80 & 24 & 5 & 20.8 & 24 & 2 & 8.3 \\
\hline $95 \%$ probity & \multicolumn{3}{|c|}{379 copies/ml [interval: $250-907$ copies $/ \mathrm{ml}$ ] } & \multicolumn{3}{|c|}{384 copies/ml [interval: $268-737$ copies/ml] } \\
\hline
\end{tabular}


(a)

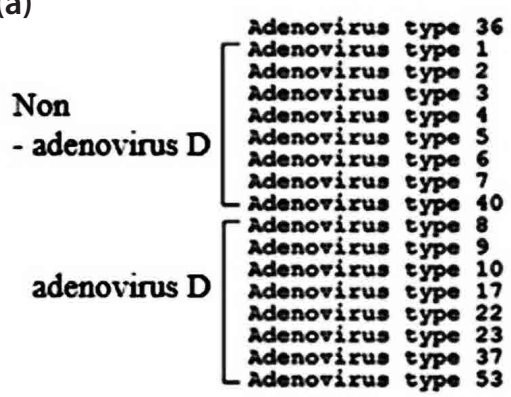
Adenovirus type 36 Adenovirus typo Adenorirus type Adenovirug eype - adenovirus D $\left[\begin{array}{l}\text { Adenovirug type } \\ \text { Adenovirus type } 5 \\ \text { Adenovirus type } 6 \\ \text { Adenovirug type } 7 \\ \text { Adenorirus type } 40\end{array}\right.$ - adenovirus D $\left[\begin{array}{l}\text { Adenovirug type } \\ \text { Adenovirus type } 5 \\ \text { Adenovirus type } 6 \\ \text { Adenovirug type } 7 \\ \text { Adenorirus type } 40\end{array}\right.$ - adenovirus D $\left[\begin{array}{l}\text { Adenovirug type } \\ \text { Adenovirus type } 5 \\ \text { Adenovirus type } 6 \\ \text { Adenovirug type } 7 \\ \text { Adenorirus type } 40\end{array}\right.$

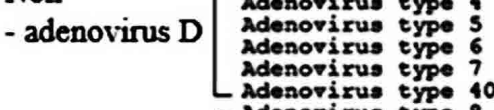
Adenovirus type 8 adenorizus type 10 Adenovirus type 17 Adenovirus type 22 Adenovirus typo 23 adenorirus type 53

(b)

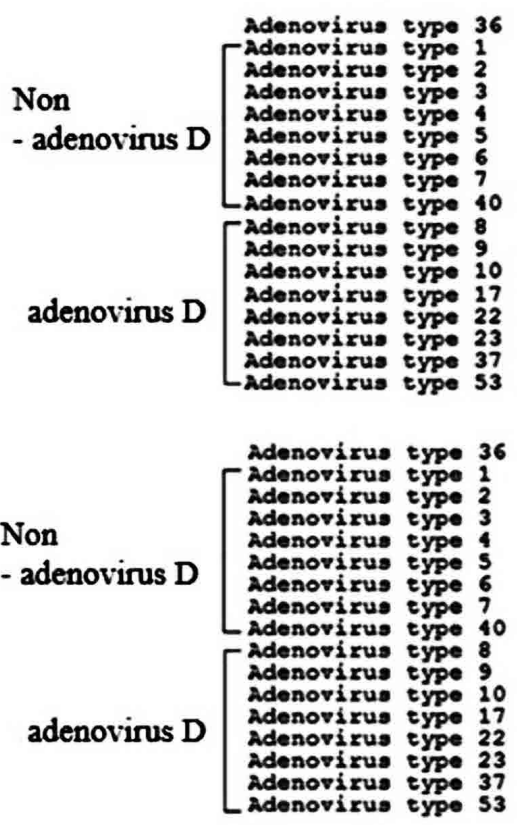

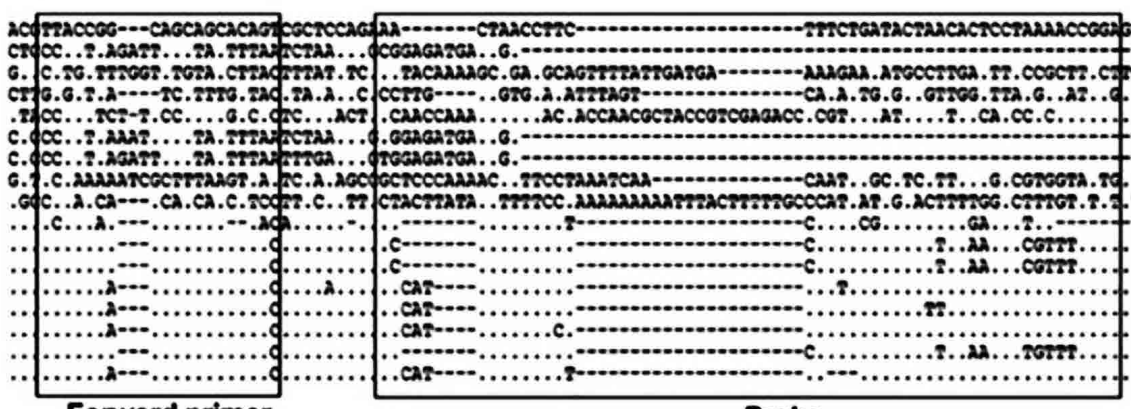

Fonward primer

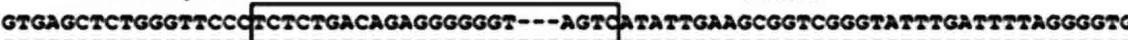

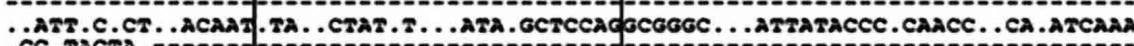

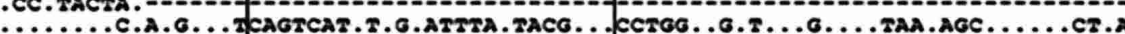
- c.

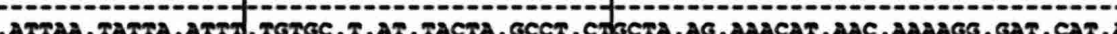

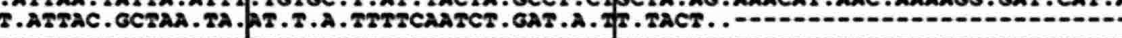
croas

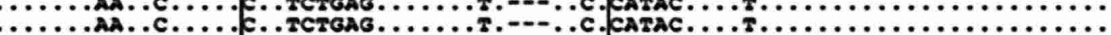

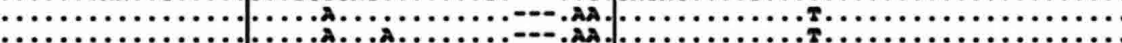

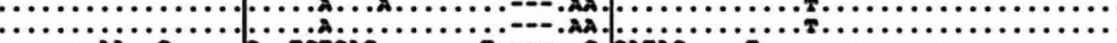

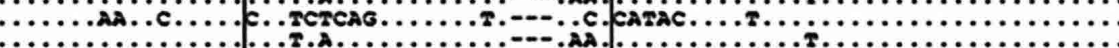

\section{Reverse primer}

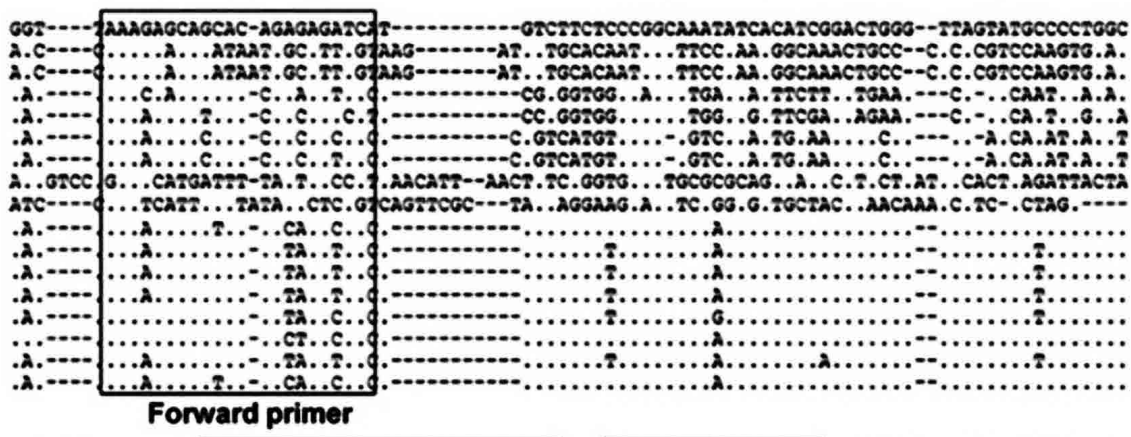

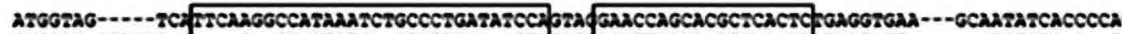

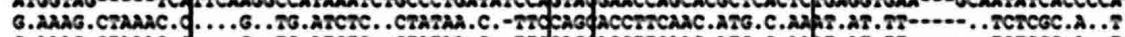

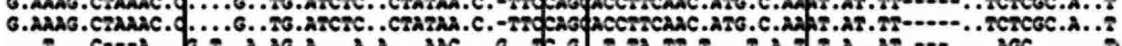

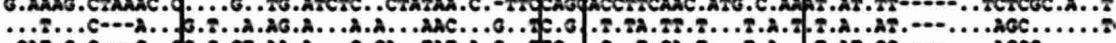

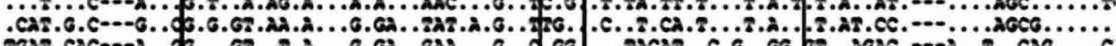

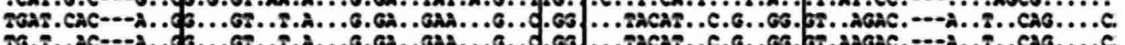
ro...AC--A. ca.rag.zacagcad . (n)

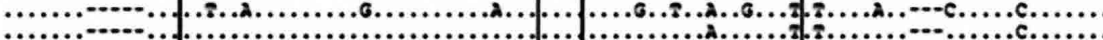

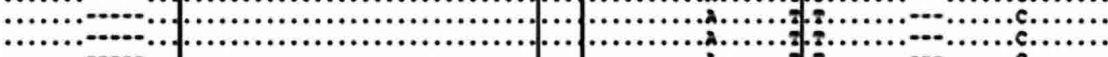

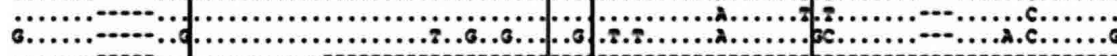

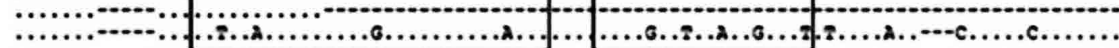
Probe

Reverse primer

Fig. 3

Alignment of $E 3$ and E4orf 1 gene sequences of adenoviruses

The sequences obtained from E3 (a) and E4orf1 (b) genes have been deposited in GenBank Acc. Nos. AF534906 (adenovirus 1), J01917 (adenovirus 2), DQ086466 (adenovirus 3), KX384957 (adenovirus 4), AY601635 (adenovirus 5), LC068720 (adenovirus 6), AY921615 (adenovirus 7), KT862547 (adenovirus 8), AJ854486 (adenovirus 9), JN226746 (adenovirus 10), HQ910407 (adenovirus 17), FJ404771 (adenovirus 22), KF279629 (adenovirus 23), DQ900900 (adenovirus 37), KU162869 (adenovirus 40), AB605246 (adenovirus 53), and GQ384080 (adenovirus 36). Primer and probe sequences are boxed and labeled. The multiple sequence alignment was performed using ClustalW, based on the similarities among adenovirus groups. 
Table 5. Detection of adenovirus DNAs by quantitative real-time PCR of several gene regions

\begin{tabular}{|c|c|c|c|c|c|}
\hline \multirow{2}{*}{ Virus type } & \multicolumn{5}{|c|}{ Quantitative PCR for detection of adenovirus $36 \mathrm{Ct}$} \\
\hline & Hexon 1 & Hexon 2 & Fiber & E3 & E4orf1 \\
\hline Adenovirus type $1^{\text {a }}$ & $\mathrm{No} C t$ & $\mathrm{No} C t$ & $\mathrm{No} C t$ & No Ct & No Ct \\
\hline Adenovirus type $2^{\mathrm{a}}$ & No Ct & No Ct & No Ct & No Ct & No Ct \\
\hline Adenovirus type $3^{\mathrm{a}}$ & No Ct & No Ct & No Ct & No Ct & No Ct \\
\hline Adenovirus type $4^{\mathrm{a}}$ & No Ct & No Ct & No Ct & No Ct & No Ct \\
\hline Adenovirus type $5^{\mathrm{a}}$ & No Ct & No Ct & No Ct & No Ct & No Ct \\
\hline Adenovirus type $6^{\mathrm{a}}$ & No Ct & No Ct & No Ct & No Ct & No Ct \\
\hline Adenovirus type $7^{\mathrm{a}}$ & 39.95 & 19.55 & 11.12 & No Ct & No Ct \\
\hline Adenovirus type $10^{\mathrm{a}}$ & 35.64 & No Ct & 36.32 & No Ct & No Ct \\
\hline Adenovirus type $23^{a}$ & 12.73 & 15.93 & 37.50 & No Ct & No Ct \\
\hline Adenovirus type $36^{\mathrm{b}}$ & 10.93 & 11.75 & 11.87 & 10.55 & 11.58 \\
\hline Adenovirus type $40^{\mathrm{a}}$ & No Ct & No Ct & 42.31 & No Ct & No Ct \\
\hline
\end{tabular}

${ }^{a}$ All viral genomic DNAs were provided by H. Lee, Department of Microbiology, University of Ulsan. ${ }^{\text {bAd}} 36$ was purchased from the American Type Culture Collection (ATCC).

$10^{4}$ copies $/ \mathrm{ml}$ in the E3-specific qPCR, and 4.14 for $10^{6}$ copies $/ \mathrm{ml}$ and 1.07 for $10^{4}$ copies $/ \mathrm{ml}$ in the E4orf1-specific qPCR (Table 6). In this experiment, all intra-assay and inter-assay $\%$ CVs were less than $20 \%$, confirming high reproducibility.

Evaluation of the standard qPCR method using mouse samples

After developing the standard qPCR method to detect Ad36 DNA, we wanted to test it using in vivo samples. However, because of difficulties in obtaining samples of human adipocytes, which may be considered the primary target of Ad36 infection (Krishnapuram et al., 2011; Dhurandhar, 2001; Pasarica and Dhurandhar, 2007), we established a surrogate mouse model. In addition, it has not been clear whether the infection route of $\mathrm{Ad} 36$ is oral and/or respiratory, and which organs are the primary target. The analysis of mouse organ samples after Ad36 infection using the standard qPCR developed in this study may assist in resolving these questions.

We investigated the distribution of Ad36 DNA in four organs after infection of mice with Ad36 via three routes (intraperitoneal, intranasal, and oral). Tissues tested were epididymal fat, liver, and pancreas, which are organs with major metabolic roles, and lungs, which are the major target for respiratory viruses. We infected mice with Ad36 via each route (15 mice per route) and euthanized the mice 1 , $3,7,30$, and $90 \mathrm{dpi}(\mathrm{n}=3 \mathrm{mice} /$ group at each time point) to determine the distribution of the viral DNA. There was no detectable Ad36 DNA in the liver, epididymal fat, lungs, or pancreas at any time point $(1,3,7,30$, or $90 \mathrm{dpi})$ in mice infected via the oral route (Fig. 4). However, Ad36 DNA was consistently detected in the lungs at $30 \mathrm{dpi}$ via the intranasal route. In contrast with the lungs, Ad36 DNA was not detected in epididymal fat, liver, and pancreas neither at 30 nor by 90 days after intranasal infection (Fig. 4).

\section{Discussion}

The diagnostics of adenovirus infection can be achieved by virus isolation in cell culture (tissue culture infective dose 50, TCID $_{50}$ ), antigen/antibody-based methods (immunofluorescence, enzyme immunoassays, serum neutralization test, and

Table 6. Intra- and inter-assay variabilities of plasmid standards using quantitative PCR for detection of adenovirus 36

\begin{tabular}{|c|c|c|c|c|c|c|c|}
\hline \multirow[b]{2}{*}{ Variation } & \multirow{2}{*}{$\begin{array}{l}\text { Copies } / \mathrm{ml} \text { of } \\
\text { plasmid standard }\end{array}$} & \multicolumn{3}{|c|}{ Adenovirus 36 DNA copies/ml (E3 gene) } & \multicolumn{3}{|c|}{ Adenovirus 36 DNA copies/ml (E4orf1 gene) } \\
\hline & & $\begin{array}{c}\text { Mean quantity } \\
\text { (copies/ml) }\end{array}$ & $\begin{array}{l}\text { Standard } \\
\text { deviation }\end{array}$ & $\% \mathrm{CV}^{\mathrm{a}}$ & $\begin{array}{l}\text { Mean quantity } \\
\text { (copies/ml) }\end{array}$ & $\begin{array}{l}\text { Standard } \\
\text { deviation }\end{array}$ & $\% \mathrm{CV}^{\mathrm{a}}$ \\
\hline \multirow[t]{2}{*}{ Intra-assay $(\mathrm{n}=20)^{\mathrm{b}}$} & $1 \times 10^{6}$ & 1091852.46 & 60984.49 & 5.59 & 1270681.24 & 63489.69 & 5.00 \\
\hline & $1 \times 10^{4}$ & 9461.82 & 1231.63 & 13.02 & 12518.34 & 1395.80 & 11.15 \\
\hline \multirow[t]{2}{*}{ Inter-assay $(\mathrm{n}=20)^{\mathrm{b}}$} & $1 \times 10^{6}$ & 1111728.33 & 88775.92 & 7.99 & 946623.90 & 39267.42 & 4.14 \\
\hline & $1 \times 10^{4}$ & 10335.42. & 1003.71 & 9.71 & 9355.58 & 977.13 & 1.07 \\
\hline
\end{tabular}

a $\% \mathrm{CV}$ : percent coefficient of variation. ${ }^{\mathrm{b}}$ duplicates, 10 days. 
(a)

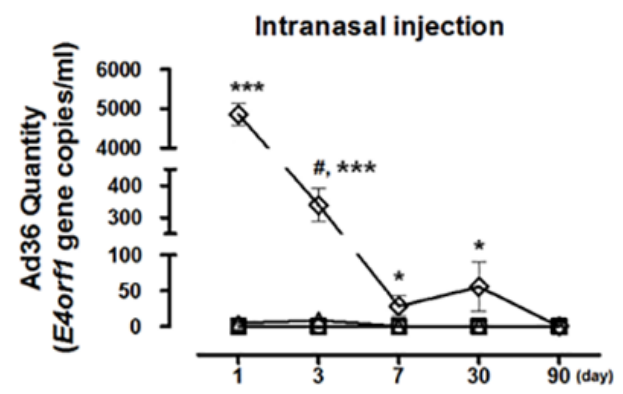

(c)

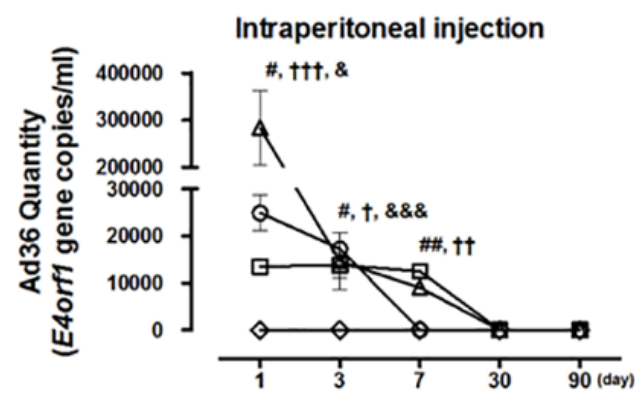

(b)

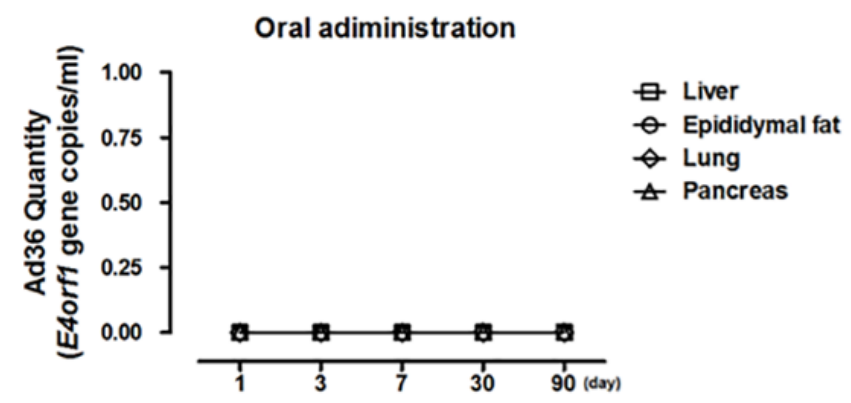

(d)

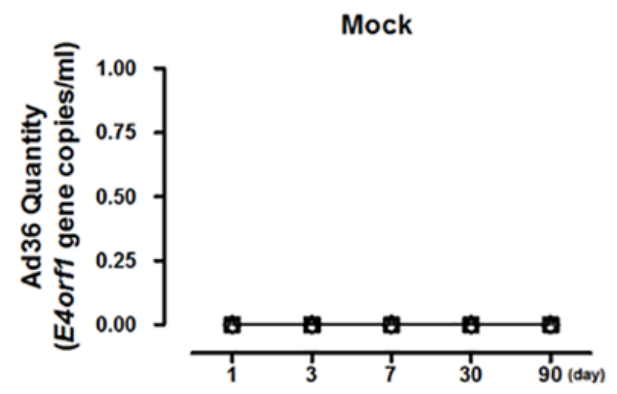

Fig. 4

Detection of Ad36 DNA in organs from infected mice

Ad36 DNA was analyzed in epididymal fat, liver, and pancreas of Ad36-infected mice at 1, 3, 7, 30, and 90 dpi ( $\mathrm{n}=3 /$ group). Intranasal, oral, and intraperitoneal routes were used for infection. Mock indicates organs from non-infected mice. Comparisons were made between the mock-infected and infected organs at the same times post infection ( ${ }^{*}$; lung vs. mock, \#; pancreas vs. mock, $\dagger$; liver vs. mock, and \&; epididymal fat vs. mock). ${ }^{*}, \#, \&$, and $\dagger$ indicate $P<0.05$. \#\# indicate $P<0.005$. ${ }^{* * *}, \dagger \dagger \dagger$, and $\& \& \&$ indicate $P<0.001$. The copies $/ \mathrm{ml}$ are shown as mean \pm standard deviation (SD) and differences assessed using $t$ tests. All analyses were performed using GraphPad Prism v. 5.01.

immunochromatography), or nucleic acid amplification tests (Al-Siyabi et al., 2013). Most previous reports have examined Ad36-specific antibodies in test serum using a serum neutralization test (Atkinson et al., 2005; Na et al., 2010; Atkinson et al., 2010). However, the presence of Ad36-specific antibody merely indicates past infection with Ad36. Therefore, others have attempted to directly detect Ad36 DNA in the samples. Salehian et al. found Ad36 DNA in the adipose tissue of a patient with unusual visceral obesity (Salehian et al., 2010), and Ponterio and Gnessi (2015) clearly demonstrated Ad36 DNA in 4 of 21 adipose tissue samples from obese or overweight adults. However, both groups used predominantly a conventional PCR-based method to detect Ad36 DNA. It may be less sensitive and specific than real-time PCR. Therefore, it would be extremely useful to develop a rapid and reliable standard method to detect Ad36 DNA that indicates current Ad36 infection.

In this study, we developed a standard method for viral DNA extraction and qPCR for the detection and quantification of Ad36 DNA. We selected the E3 and E4orf1 regions for amplification because these regions showed no conserved sequences with other adenoviruses. Furthermore, for our method we used the TaqMan probe system because it has a high sensitivity and specificity.

Since Ad36 is a DNA virus, the efficiency of the viral DNA extraction method is critical to maximize the sensitivity of the standard diagnostic method. Therefore, we tested five commercial DNA extraction kits, and selected the QIAGEN method because of its good performance in DNA-purification and its price-performance ratio. As shown above, the standard protocol established in this study to detect Ad36 genome showed very high reproducibility, sensitivity and specificity.

To evaluate if the newly developed quantitative PCR would also be applicable to tissue samples from clinical cases, we tested samples from Ad36-infected mice as a surrogate model for human clinical samples. We infected mice with Ad36 via three routes (oral, intranasal, and intraperitoneal as positive control) to determine which mouse organ is the primary target. We showed that there was no detectable 
Ad36 E4orf1 in the liver, epididymal fat, lungs, or pancreas at any time point $(1,3,7,30$, or $90 \mathrm{dpi})$ in mice infected via the oral route. These data suggest that orally administered Ad36 cannot infect the gastrointestinal tract or may be immediately eliminated by host immune responses such as those triggered by TLRs or the respiratory immune system. In contrast, Ad36 DNA was detected in the lungs 30 days after infection via the intranasal route. Coxsackievirus and adenovirus receptor (CAR), the receptor for Ad36, is internalized by cells together with adenovirus after infection. Furthermore, a CAR isoform, $\mathrm{CAR}^{\mathrm{Ex} 8}$, is well expressed in human epithelial cells of the respiratory tract and is localized to the apical region of airway epithelia (Excoffon et al., 2010). Therefore, it suggested that $\mathrm{CAR}^{\mathrm{Ex} 8}$ may contribute to the greater persistence of Ad36 in respiratory organs. A previous study showed that Ad36 could be transmitted from Ad36infected mice to uninfected mice co-housed in the same cage (Krishnapuram et al., 2011). This suggests that the respiratory system may be one route of viral transmission. Although our data showed that Ad36 DNA disappeared early after viral infection, the previous co-housing study reported that Ad36 DNA was present for up to 12 weeks (Krishnapuram et al., 2011). We assume that these differences might be related to the disparity of detection methods and viral infection routes. In conclusion, we found that Ad36 DNA remains in mouse lungs for at least 30 days after viral infection via the respiratory tract. This suggests that natural infection path of Ad36 may be via the respiratory tract. Although the first isolation of adenovirus was performed using adenoid-tissue-derived cell culture, recent reports showed that the gastrointestinal tract, as well as the respiratory tract, shed human adenovirus for weeks or longer (Scott et al., 2016). Moreover, a latent stage of adenoviral infection was found to persist in tonsillar lymphocytes in almost $80 \%$ of the children investigated (Lion, 2014). However, further investigation is necessary to understand how Ad36 is transmitted and how long it can persist in organs. The qPCR method developed here can be a useful tool to help elucidating these questions. In fact, a previous report showed that adenoviruses had a cytopathic effect in cells from Madin-Darby canine kidneys, rhesus monkey kidneys, and human lung carcinoma (Leonardi et al., 1995). Therefore, assuming that if the samples cultured in the cells mentioned above were subjected to the qPCR method developed in this study, the sensitivity of Ad36 DNA detection would increase.

Overall, our results suggest that the TaqMan probe qPCR for Ad36 may have value in clinical studies; for example, a patient could be rapidly diagnosed at the time of virus infection before obesity develops. Further studies of the qPCR method with human samples will be performed in the future.

Acknowledgments. This work was supported by the Catholic University of Korea, Research Fund, 2018, a grant from the Korean
Health Technology R\&D Project through the KHIDI, funded by the Ministry of Health \& Welfare, Republic of Korea (HI15C2955), a grant (16172MFDS363) from Ministry of Food and Drug Safety in 2017-2018, and Basic Science Research Program through the NRF, which is funded by the Ministry of Science, ICT \& Future Planning (NRF-2015M3A9B5030157). All authors are the guarantors for this work, and had full access to all of the data in the study and take responsibility for the integrity of the data and the accuracy of the data analysis. We thank the researchers at Catholic University Viral Immunology Lab and Genetree Research Company for helpful discussions and their technical assistance.

\section{References}

Adrych K (2005): Can obesity be infectious? Przegl. Lek. 62, 916-918.

Al-Siyabi T, Binkhamis K, Wilcox M, Wong S, Pabbaraju K, Tellier R, Hatchette TF, LaBlanc JJ (2013): A cost effective real-time PCR for the detection of adenovirus from viral swabs. Virol. J. 10, 184. https://doi.org/10.1186/1743$\underline{422 X-10-184}$

Astrup A, Lundsgaard C, Stock MJ (1998): Is obesity contagious? Int. J. Obes. Relat. Metab. Disord. 22, 375-376. https:// doi.org/10.1038/sj.ijo.0800614

Atkinson RL, Dhurandhar NV, Allison DB, Bowen RL, Israel BA, Albu JB, Augustus AS (2005): Human adenovirus-36 is associated with increased body weight and paradoxical reduction of serum lipids. Int. J. Obes. (Lond) 29, 281-286. https://doi.org/10.1038/sj.ijo.0802830

Atkinson RL, Lee I, Shin HJ, He J (2010): Human adenovirus-36 antibody status is associated with obesity in children. Int. J. Pediatr. Obes. 5, 157-160. https://doi. org/10.3109/17477160903111789

Davison AJ, Benko M, Harrach B (2003): Genetic content and evolution of adenoviruses. J. Gen. Virol. 84, 2895-2908. https://doi.org/10.1099/vir.0.19497-0

Dhurandhar NV (2001): Infectobesity: obesity of infectious origin. J. Nutr. 131, 2794S-2797S. https://doi.org/10.1093/ jn/131.10.2794S

Dhurandhar NV, Whigham LD, Abbott DH, Schultz-Darken NJ, Israel BA, Bradley SM, Kemnitz JW, Allison DB, Atkinson RL (2002): Human adenovirus Ad-36 promotes weight gain in male rhesus and marmoset monkeys. J. Nutr. 132, 3155-3160. https://doi.org/10.1093/jn/131.10.3155

Echavarria M, Forman M, Ticehurst J, Dumler JS, Charache P (1998): PCR method for detection of adenovirus in urine of healthy and human immunodeficiency virus-infected individuals. J. Clin. Microbiol. 36, 3323-3326.

Echavarria M (2008): Adenoviruses in immunocompromised hosts. Clin. Microbiol. Rev. 21, 704-715. https://doi. org/10.1128/CMR.00052-07

Excoffon KJDA, Gansemer ND, Mobily ME, Karp PH, Parekh KR, Zabner J (2010): Isoform-specific regulation and localization of the coxsackievirus and adenovirus receptor in human airway epithelia. PLoS One 5, e9909 https://doi. org/10.1371/journal.pone.0009909 
Gu Z, Belzer SW, Gibson CS, Bankowski MJ, Hayden RT (2003): Multiplexed, real-time PCR for quantitative detection of human adenovirus. J. Clin. Microbiol. 41, 4636-4641. https://doi.org/10.1128/JCM.41.10.4636$\underline{4641.2003}$

Halbert DN, Cutt JR, Shenk T (1985): Adenovirus early region 4 encodes functions required for efficient DNA replication, late gene expression, and host cell shutoff. J. Virol. $56,250-257$

Heim A, Ebnet C, Harste G, Pring-Akerblom P (2003): Rapid and quantitative detection of human adenovirus DNA by real-time PCR. J. Med. Virol. 70, 228-239. https://doi. org/10.1002/jmv.10382

Krishnapuram R, Kirk-Ballard H, Zuberi A, Dhurandhar NV (2011): Infectivity period of mice inoculated with human adenoviruses. Lab. Anim. 45, 103-108. https://doi. org/10.1258/la.2010.010084

Leonardi GP, Costello P, Harris P (1995): Use of continuous human lung cell culture for adenovirus isolation. Intervirology 38, 352-355. https://doi.org/10.1159/000150463

Lion T (2014): Adenovirus infections in immunocompetent and immunocompromised patients. Clin. Microbiol. Rev. 27, 441-462. https://doi.org/10.1128/CMR.00116-13

Miura-Ochiai R, Shimada Y, Konno T, Yamazaki S, Aoki K, Ohno S, Suzuki E, Ishiko H (2007): Quantitative detection and rapid identification of human adenoviruses. J. Clin. Microbiol. 45, 958-967. https://doi.org/10.1128/ JCM.01603-06

Na HN, Hong YM, Kim J, Kim HK, Jo I, Nam JH (2010): Association between human adenovirus-36 and lipid disorders in Korean school children. Int. J. Obes. (Lond) 34, 89-93. https://doi.org/10.1038/ijo.2009.207

$\mathrm{Na} \mathrm{HN}$, Kim H, Nam JH (2012): Novel genes and cellular pathways related to infection with adenovirus- 36 as an obesity agent in human mesenchymal stem cells. Int. J. Obes. (Lond) 36, 195-200. https://doi.org/10.1038/ijo.2011.89

Nemerow GR, Pache L, Reddy V, Stewart PL (2009): Insights into adenovirus host cell interactions from structural studies. Virology 384, 380-388. https://doi.org/10.1016/j. virol.2008.10.016

Pasarica M, Shin AC, Yu M, Ou Yang HM, Rathod M, Jen KL, Mohan Kumar S, Mohan Kumar PS, Markward N, Dhurandhar NV (2006): Human adenovirus 36 induces adiposity, increases insulin sensitivity, and alters hypothalamic monoamines in rats. Obesity (Silver Spring) 14, 1905-1913. https://doi.org/10.1038/oby.2006.222

Pasarica M, Dhurandhar NV (2007): Infectobesity: obesity of infectious origin. Adv. Food. Nutr. Res. 52, 61-102. https://doi. org/10.1016/S1043-4526(06)52002-9

Ponterio E, Gnessi L (2015): Adenovirus 36 and Obesity: An Overview. Viruses 7, 3719-3740. https://doi.org/10.3390/ v7072787

Ponterio E, Cangemi R, Mariani S, Casella G, De Cesare A, Trovato FM, Garozzo A, Gnessi L (2015): Adenovirus 36 DNA in human adipose tissue. Int. J. Obes. (Lond) 39, 1761-1764. https://doi.org/10.1038/ijo.2015.163

Powledge TM (2004): Is obesity an infectious disease? Lancet Infect. Dis. 4, 599. https://doi.org/10.1016/S14733099(04)01164-8

Roberts MM, White JL, Grutter MG, Burnett RM (1986): Threedimensional structure of the adenovirus major coat protein hexon. Science 232, 1148-1151. https://doi. org/10.1126/science. 3704642

Robinson CM, Seto D, Jones MS, Dyer DW, Chodosh J (2011): Molecular evolution of human species $\mathrm{D}$ adenoviruses. Infect. Genet. Evol. 11, 1208-1217. https://doi.org/10.1016/j. meegid.2011.04.031

Robinson CM, Singh G, Lee JY, Dehghan S, Rajaiya J, Liu EB, Yousuf, Betensky RA, Jones MS, Dyer DW, Seto D, Chodosh J (2013): Molecular evolution of human adenoviruses. Sci. Rep. 3, 1812.

Rogers PM, Fusinski KA, Rathod MA, Loiler SA, Pasarica M, Shaw MK, Kilroy G, Sutton GM, McAllister EJ, Mashtalir N, Gimble JM, Holland TC, Dhurandhar NV (2008): Human adenovirus Ad-36 induces adipogenesis via its E4 orf-1 gene. Int. J. Obes. (Lond) 32, 397-406. https://doi. org/10.1038/sj.ijo.0803748

Salehian B, Forman SJ, Kandeel FR, Bruner DE, He J, Atkinson RL (2010): Adenovirus 36 DNA in adipose tissue of patient with unusual visceral obesity. Emerg. Infect. Dis. 16, 850-852. https://doi.org/10.3201/eid1605.091271

Scott MK, Chommanard C, Lu X, Appelgate D, Grenz L, Schneider E, Gerber SI, Erdman DD, Thomas A (2016): Human adenovirus associated with severe respiratory infection, Oregon, USA, 2013-2014. Emerg. Infect. Dis. 22, 1044-1051. https://doi.org/10.3201/eid2206.151898

Sun Y, Zhao L, Zhao M, Zhu R, Deng J, Wang F, Li F, Ding Y, Tian R, Qian Y (2014): Four DNA extraction methods used in loop-mediated isothermal amplification for rapid adenovirus detection. J. Virol. Methods 204, 49-52. https://doi. org/10.1016/j.jviromet.2014.04.006

van Tongeren SP, Degener JE, Harmsen HJ (2011): Comparison of three rapid and easy bacterial DNA extraction methods for use with quantitative real-time PCR. Eur. J. Clin. Microbiol. Infect. Dis. 30, 1053-1061. https://doi. org/10.1007/s10096-011-1191-4

Wadell G (1984): Molecular epidemiology of human adenoviruses. Curr. Top. Microbiol. Immunol. 110, 191-220. https://doi. org/10.1007/978-3-642-46494-2 7

Walsh MP, Seto J, Jones MS, Chodosh J, Xu W, Seto D (2010): Computational analysis identifies human adenovirus type 55 as a re-emergent acute respiratory disease pathogen. J. Clin. Microbiol. 48, 991-993. https://doi.org/10.1128/ JCM.01694-09

Wold WS, Gooding LR (1991): Region E3 of adenovirus: a cassette of genes involved in host immunosurveillance and virus-cell interactions. Virology 184, 1-8. https://doi. org/10.1016/0042-6822(91)90815-S 